\title{
ELECTRONIC COOLING SYSTEMS BASED ON FIXED-VALVE MICROPUMP NETWORKS
}

\author{
Christopher J. Morris, Jone Y. Chung, Patricia E. Rahm and Fred K. Forster \\ Department of Mechanical Engineering, University of Washington \\ Seattle, WA 98195-2600 USA \\ Dan Faulkner and Reza Shekarriz \\ MicroEnergy Technologies, Inc. \\ Vancouver, WA 98660
}

\begin{abstract}
Thermal control of electronics in portable computers and space vehicles where compactness, weight, efficiency, simplicity, reliability and cost are important is an area ideally targeted for MEMS-based approaches. Micropumps based on diaphragm actuation and utilizing fixed-geometry valves may meet all the above criteria when used for fluid transport in closed-loop forced-convection thermal management systems. To investigate this potential application, an integrated cooling module was designed, fabricated and tested. It consisted of a network of four planar micropumps fabricated in plastic and a copper microchannel heat sink. Plastic allowed rapid prototyping and resulted in a multilayer pump network $32 \times 32$ by $11 \mathrm{~mm}$ thick. Other materials could reduce the total thickness significantly. To our knowledge this work is the first application of a scalable network of micropumps. Thermal power handling of $35 \mathrm{~W}$ was possible at a flow rate of $11 \mathrm{ml} / \mathrm{min}$ using water as the coolant.
\end{abstract}

\section{INTRODUCTION}

Cooling individual electronic components and systems where mass and reliability are extremely important, such as on micro-satellites is receiving significant attention. In addition, size, efficiency and cost are critical factors in the choice of thermal management method for portable computers. While a number of approaches have been reported, such as thermosyphons [1] electroosmotic forced convection [2] and spray cooling[3], optimization of all characteristics for specific applications is far from complete. In space applications, single-phase cooling may be the proper choice for highest reliability when conductive heat transfer is insufficient. In other applications, two-phase cooling may be the best choice even though pressure and flow instabilities pose problems and driving pressure required increases dramatically with small increases in vapor to liquid mass ratio (quality) [4].

In this study we investigated the use of planar membrane micropumps that utilized fixed-geometry valves, which are simple to fabricate and have no moving parts except for the flexure of a piezoelectrically or electrostatically driven membrane [5-7]. These pumps currently do not produce the high pressure of electroosmotic pumps, but are attractive in many if not all other ways previously mentioned. Presented here are our initial efforts to utilize this approach

* Travel support has been generously provided by the Transducers Research Foundation and by the DARPA MEMS and DARPA BioFlips programs. in the form of a pump network fabricated in plastic. The network was configured in parallel to achieve high flow, but could be configured in series to develop higher pressure necessary for two-phase cooling. We know of no other reports of scalable networks of micropumps.

\section{MICROPUMP-HEAT EXCHANGER MODULE}

One overall goal of this project was to develop a compact micropump/heat exchanger unit, the design of which is shown in Fig. 1. The Teflon fluid distribution block and inletoutlet header were designed to accommodate various $1 \mathrm{~cm}^{2}$ microchannel arrays. For this initial study v-shaped channels approximately $60 \mu \mathrm{m}$ wide and $200 \mu \mathrm{m}$ deep produced with laser micromachining were utilized (Pacific Northwest National Laboratory, Richland, WA). The unit was also designed to accommodate a combination of stacked planar micropumps as shown. For this study a network of four micropumps arranged in parallel was used to attain relatively high flow rate. The piezoelectric drivers were arranged electrically in pairs as shown schematically in Fig. 2. To eliminate the need for a fluid capacitor between the pump network and the fluid load, the individual pumps in each pair operated in phase while each pair operated out of phase from the other.

Reduced-order linear system modeling was used to maximize pump resonance and evaluate numerous design parameters [8]. Since the planform dimensions were fixed at $2.5 \mathrm{~cm}^{2}$, and since the target flow rate was higher than we had attempted with past pump designs, the starting point for the design process was a $20 \mathrm{~mm}$ diameter pump chamber diameter. With that dimension fixed, most of the other parameters were determined through the design for resonance described above using properties of acrylic. However, although valve size was determined by this design process, valve shape was not. Figure 3 shows two pump layers, each utilizing different Tesla-type valves designs. The one used in the pump labeled fvp1 has been used in a number of other pump designs, while that used in pump fvp2 was determined from a computational fluid dynamics-based optimization process that substantially improved single-chamber pump performance $[\mathbf{9}]$.

Machining of all pump features was accomplished with miniature end mills ranging from 125 to $1700 \mu \mathrm{m}$ in diameter. SurfCAM (CNC Prose) was used to translate CAD drawings into machine code for a mini-milling machine (Model 5410, Sherline Products Inc., Vista, CA), modified for numerical control (999-6100-005, MicroKinetics Corp., Kennesaw, GA). This process allowed rapid prototyping 


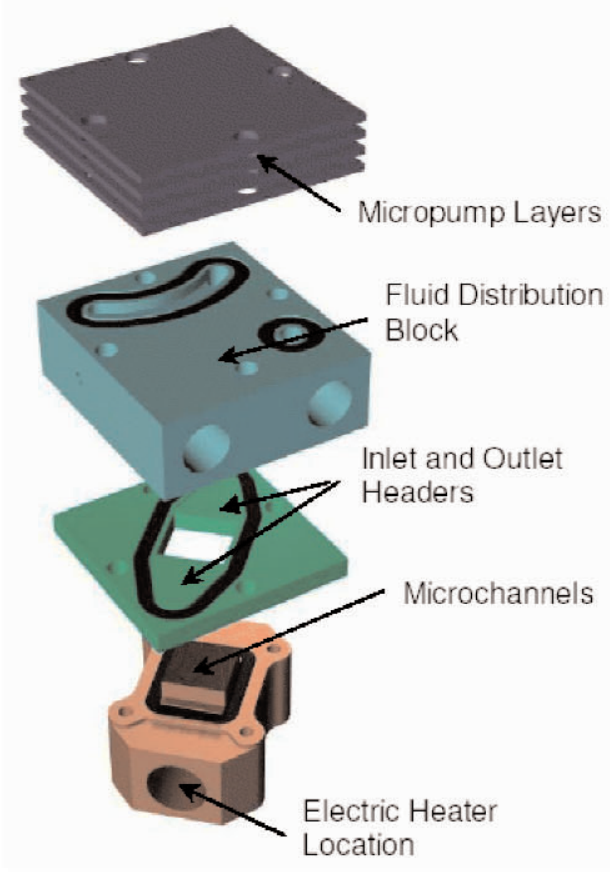

Figure 1. Schematic of the prototype pump/heat sink assembly. The pump network consisted of a stacked array of micropumps to demonstrate scalability of fluid transport without increase in footprint size.

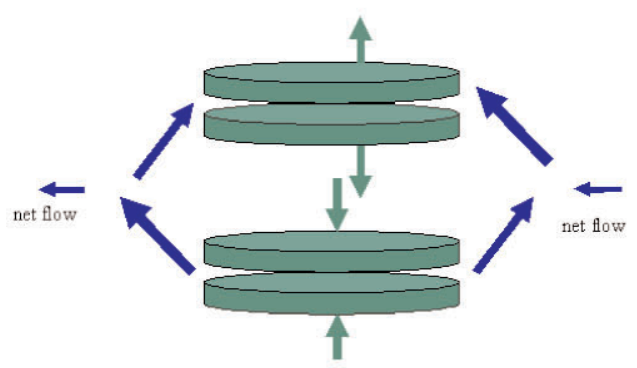

Figure 2. Schematic of how two pairs of actuators operating out of phase with the elements in each pair operating in phase and deliver steady flow at the network outlet. Two pump chambers are positioned in between each pair of actuators. Arrows are shown for one half of a pump cycle, with relative flow magnitudes into and out of each pump chamber shown.

comparcd with silicon-based microfabrication. The process also allowed easy three-dimensional profiling of multipledepth features, such as the transition between deep valves and shallow chambers as shown in Fig. 4.

Two machined $1.6 \mathrm{~mm}$ acrylic layers of the type shown in Figs. 3(a) and (b) were used in each of two pump pairs, separated by a plain $0.5 \mathrm{~mm}$ polycarbonate layer. A total of nine layers comprised the pump network, six for the two pairs of pumps. The seventh was a $3.2 \mathrm{~mm}$ acrylic spacer be-

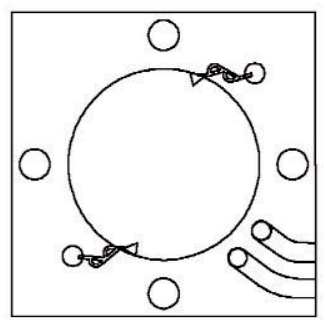

(a) fvp1

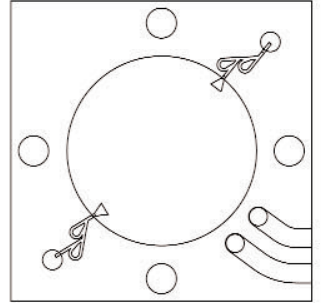

(b) $f_{v p} 2$
Figure 3. Valve-pump chamber layers for micropump network. Shown are $20 \mathrm{~mm}$ diameter pump chambers, two-element valves, each having a transverse dimension of $300 \mu \mathrm{m}$ : (a) the Tesla-type A for the pump fvp 1 and (b) the Tesla-type G for pump fvp2. Also shown are four through holes for attachment to the heat exchanger and channels at the lower-right corner for routing electrical connections.

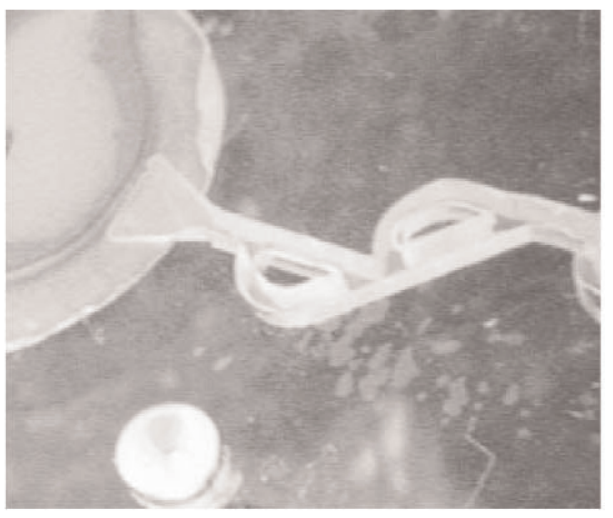

Figure 4. Valve fabricated in acrylic using micro milling techniques.

tween pump pairs with a cavity milled on each side to allow for actuator clearance. The eighth and ninth acrylic layers, cach $1.6 \mathrm{~mm}$ thick, formed a bearing surface for the fluid distribution block and accommodated variable spacing between valve ends (see Figs. 1 and 3). Rapid cure cyanoacrylate (Loctite 420 Superbonder) was used to bond all plastic laycrs except the acrylic spacer, which was bonded with cpoxy. Cyanoacrylate was also used to bond the piczoclectric driver elements to the appropriate acrylic layer. The height of the completed network stack was $11 \mathrm{~mm}$ with transverse dimensions of $32 \mathrm{~mm}$.

\section{TEST METHODS}

A micropump/heat exchanger module incorporated into a closed-loop test apparatus is shown in Fig. 5. Thermocouples were used to measure inlet and outlet coolant and cooper block temperature. Tubing carried heated coolant from the microchannel heat exchanger to a macroscopic fandriven heat exchanger in which the fluid temperature re- 


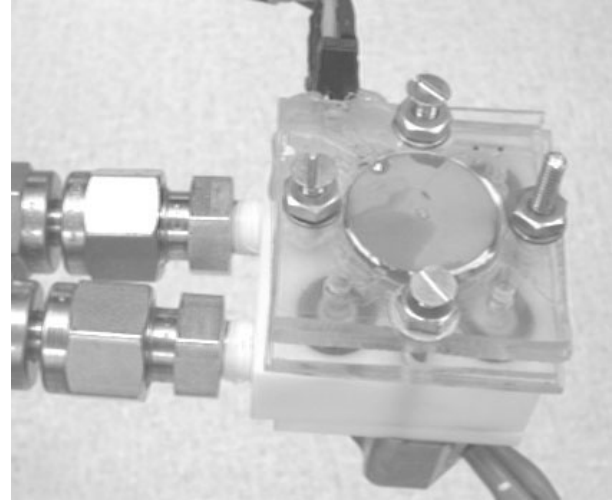

Figure 5. The pump network/heat exchanger assembly incorporated into the closed-loop test system. Electrical leads to a $400 \mathrm{~W}, 33 \Omega$ cartridge heater can be seen below the assembly.

turned to the ambient level. The cooled fluid then passed through a float-in-tube flow meter (Key Instruments, p/n GS60410, Trevose, PA) and finally returned to the micropump, which delivered it back to the microchannel array. Characterization of the test loop was performed with a syringe pump (KD Scientific, model 200, Hollistion, MA). During thermal tests the apparatus was wrapped with insulation (Kaowool S Blanket, Thermal Ceramics, Augusta, Georgia). With insulation in place, external temperatures of the tubing in the region of the coolant thermocouples differed by less than $2{ }^{\circ} \mathrm{C}$ from the coolant temperatures. Also, the electrical power delivered averaged $16 \%$ higher than the heat gain of the fluid as determined from fluid temperatures. For data taken with a micropump, deionized water was degassed by heating and the piezoelectric actuators were driven with a sinusoidal signal from a signal generator (Model 19, Wavetek, United Kingdom) and amplified (Piezo Linear Amplifier, Piezo Systems Inc., Cambridge, MA). All voltage levels are given as the amplitude of the sinusoidal signal.

\section{RESULTS AND DISCUSSION}

Pump fvp1 produced a no-load flow rate of approximately $11 \mathrm{ml} / \mathrm{min}$ at $100 \mathrm{~V}$ and $330 \mathrm{~Hz}$, which was close to model predictions. The no-load flow rate for pump fvp2 was only $4.1 \mathrm{ml} / \mathrm{min}$ at $210 \mathrm{~Hz}$, and it was not tested further. Bonding material may have been deposited in some valves causing the pump network to operate unsymmetrically with a significant reduction in performance. Data were taken for the remaining pump over four days with the system running for up to six hours, which demonstrated that dissolved gas did not pose a problem. Flow rates delivered by pump fvp1 to the microchannel heat exchanger versus heater input are shown in Fig. 6 for various pump excitation voltages. The microchannel heat exchanger temperature $T_{s}$ versus heater input is shown in Fig. 7 for the corresponding pump excitation levels. The maximum thermal power transferred to the fluid was approximately $35 \mathrm{~W}$ at $11 \mathrm{ml} / \mathrm{min}$. Some boiling occurred at all three pump excitation levels for $T_{s}>100{ }^{\circ} \mathrm{C}$.

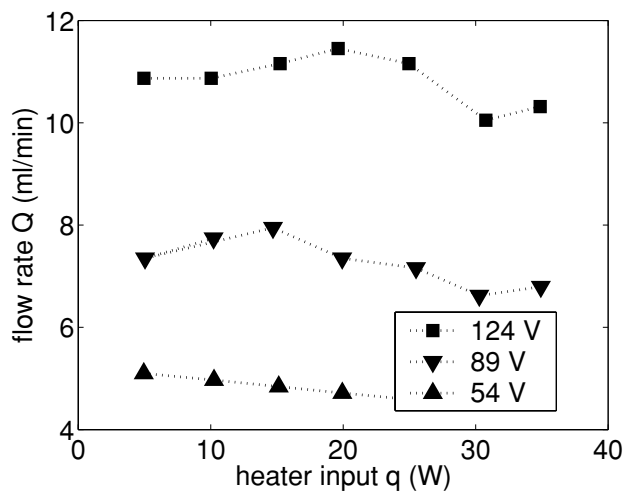

Figure 6. Flow rate delivered by micropump fvp1 at three different excitation voltage levels versus electrical power to heater. Lines added for clarity.

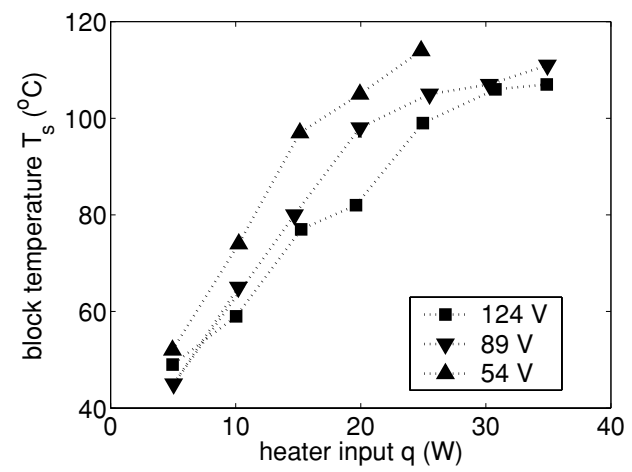

Figure 7. Heat exchanger temperature versus electrical power to heater for a range of micropump excitation voltages applied to pump fvp1. Lines added for clarity.

The junction-ambient thermal resistance ${ }^{1}$ for the highest micropump excitation level for $T_{s}<100^{\circ} \mathrm{C}$., i.e. $q<25 \mathrm{~W}$, was approximately $3 \mathrm{~K} / \mathrm{W}$. At $35 \mathrm{~W}$ it was approximately $2.3 \mathrm{~K} / \mathrm{W}$. The heat transfer coefficient for microchannel array $^{2}$ ranged from 400 to $1000 \mathrm{~W} / \mathrm{m}^{2} \mathrm{~K}$ over the range of heater input and pump excitation levels considered.

Given the number and size of piezoelectric drivers used in the pump network, an estimate was made of the peak instantaneous power $P_{o}=\pi f C V_{o}^{2}$ based on the capacitance of the drivers. For one $190 \mu \mathrm{m}$ by $18 \mathrm{~mm}$ disk of PZT5 A the capacitance $C=0.028 \mu \mathrm{F}$, based on a permittivity of $1.5 \times 10^{-2} \mu \mathrm{F} / \mathrm{m}$. For $V_{o}=100 \mathrm{~V}$ and $f=300 \mathrm{~Hz}$, $P_{o}=200 \mathrm{~mW}$. For four elements, the corresponding instantaneous power was therefore estimated to be $800 \mathrm{~mW}$. Peak power for typical single chamber pumps for which net power has been measured is 5 to 10 times higher than average power[10]. Thus, the average power of the pump network described here was estimated at between 80 and $160 \mathrm{~mW}$.

\footnotetext{
${ }^{1} \Theta_{J A}=\left(T_{s}-T_{i n}\right) / q$, where $T_{i n}$ is the inlet coolant temperature

${ }^{2} h=q / A\left(T_{s}-T_{\text {mean }}\right)$, where $A$ is the surface area of the heat exchanger, and $T_{\text {mean }}$. is the mean fluid temperature
} 


\section{CONCLUSIONS}

We have demonstrated that a fixed-valve diaphragm micropump network used in conjunction with a microchannel array was capable of handling thermal loads of $35 \mathrm{~W}$ and $35 \mathrm{~W} / \mathrm{cm}^{2}$. The prototype system, when fabricated in plastic, produced a stacked four-micropump network with a total thickness of $11 \mathrm{~mm}$. With stiffer materials, such as metal for the diaphragm, and better packaging, the overall size could be reduced significantly. Lastly, it was estimated that the net power consumption was less than $200 \mathrm{~mW}$. Thus, on the basis of these results, this approach for cooling appears to be attractive in terms of size, weight, efficiency and simplicity. Further work is needed to investigate these attributes more quantitatively along with evaluations of reliability and cost.

\section{ACKNOWLEDGMENTS}

This work was supported in part by a subcontract to the University of Washington from NASA Goddard Space Flight Center contract NASS-03059 to MicroEnergy Technologies Inc. (MET), and by Washington and Technology Center Research Technology Development Agreement WTC FTI 0310. Support was also provided by a Roy E. and Irene C. Grossmann Memorial Scholarship.

\section{REFERENCES}

[1] A. Pal, Y. Joshi, M. H. Beitelmal, C. D. Patel, and T. M. Wenger. Design and performance evaluation of a compact thermosyphon. IEEE Trans. Comp. Pack. Tech., 25(No. 4, December):601-607, 2002.

[2] L. Jiang, J. Mikkelsen, Jae-Koo Koo, D. Huber, S. Yao, L. Zhang, P. Zhou, J. G. Maveety, R. Prasher, J. G. Santiago, T. W. Kenney, and K. E. Goodson. Closed loop electroosmotic microchannel cooling system for VLSI circuits. IEEE Trans. Comp. Pack. Tech., 25(No. 3, September):347-355, 2002.

[3] C. E. Bash, C. D. Patel, and R. K. Sharma. Inkjet assisted spray cooling of electronics. In International Electronic Packaging Technical Conference and Exhibition, Maui, July 6-11 2003 (paper IPACK2003-35058).

[4] S. G. Kandlikar. Fundamental issues related to flow boiling in minichannels and microchannels. Exp. Thermal Fluid Sci., 26:389-407, 2002.

[5] F. Forster, R. Bardell, M. Afromowitz, and N. Sharma. Design, fabrication and testing of fixed-valve micropumps. In D. C. Wiggert et al., editors, Proceedings of the ASME Fluids Engineering Division, ASME International Mechanical Engineering Congress and Exposition (San Francisco), volume 234, pages 39-44, New York, November 12-17 1995. ASME.

[6] T. Gerlach and H. Wurmus. Working principle and performance of the dynamic micropump. In Micro Electro Mechanical Systems, MEMS '95 (Amsterdam), pages 221-226, New York, Jan. 29 - Feb. 2 1995. IEEE.
[7] A. Olsson, P. Enoksson, G. Stemme, and E. Stemme. A valve-less planar pump in silicon. In Transducers '95 (Stockholm), volume 2, pages 291-294, New York, June 25-29 1995. IEEE.

[8] C. J. Morris and F. K. Forster. Low-order modeling of resonance for fixed-valve micropumps based on first principles. J. Microelectromechanical Syst., 12(3):325334, 2003.

[9] A. R. Gamboa, C. J. Morris, and F. K. Forster. Optimized fixed-geometry valves for laminar flow micropumps. In ASME International Mechanical Engineering Congress and Exposition (IMECE 2003), Fluids Engineering Division, Washington, D.C., Nov. 15-21 2003 (in press \& on CD as paper IMECE2003-55036).

[10] R. Bardell, R. Sharma, F. K. Forster, M. A. Afromowitz, and R. Penney. Designing high-performance micro-pumps based on no-moving-parts valves. In L. Lin, K. E. Goodson, et al., editors, Micro-ElectroMechanical Systems (MEMS), ASME International Mechanical Engineering Congress and Exposition (Dallas), volume DSC-234/HTD-354, pages 47-53, New York, November 16-21 1997. ASME. 